\title{
Misconceptions about family planning of women in Turkey $^{1}$
}

\author{
Meltem Demirgöz $\mathrm{Bal}^{2}$ \\ Semiha Aydın Özkan ${ }^{3}$
}

\begin{abstract}
Background: The objective of this study is to investigate the myths of women about contraceptive methods.

Method: This study was planned as a cross-sectional research. The study population consisted of 1335 women aged between 16 and 56 years, who attended to a family planning clinic of a state hospital in Karaman City in the southwest part of Turkey.

Findings. The mean age of women has been $32.79 \pm 8.8$. While $6.2 \%(n=84)$ of the women used no contraceptive method, $70.4 \%(n=945)$ of them used an effective method and $23.4 \%(n=312)$ used a traditional method. The $40.2 \%$ of women have believed in that the oral contraceptive method caused weight gain, infertility, bleeding disorders, hirsutism, cancer, irritability, malformed baby and premature menopause. The $24.2 \%$ of women have thought of that the intrauterine devices caused bleeding disorder, moving in the body, cancer, decreased sexual desire, genital infection and infertility.

Conclusions: There are many myths and misconceptions surrounding contraception, and they can sometimes prevent a woman from making an informed choice.
\end{abstract}

Keywords: Misconception; Myths; Contraceptive Methods; Family Planning; Turkey

\section{Introduction}

The relationship established among population, development, and fertility in the world has led the development of first "population planning", then "birth control", and "family planning" concepts. Since these concepts are related to women status and general women health, studies have focused on women population and required including "women health" in these concepts (Ministry of Health General Directorate of Mother and Child Health and Family Planning, 2010). 1984 International Conference on Population held in Mexico City defined family planning as

\footnotetext{
1 12th Congress of the European Society of Contraception and Reproductive Health. Myths and Misconceptions Versus Evidence on Contraception 20-23 June 2012, Athens, Greece.

2 Assist. Prof., Karamanoğlu Mehmetbey University, School of Health, Nursing, meltembal@,kmu.edu.tr

${ }^{3}$ Assist. Prof., Adiyaman University, School of Health, Midwifery, saydin@adiyaman.edu.tr
} 
"individuals, having as many children as they wish, freely and wisely deciding to have intervals between the deliveries, and having information training and tools about this issue" (Brown, 1984).

Women's freedom of having as many children as they wish has an important contribution on their health, quality of life and struggle to gain identity. Therefore, family planning services on women's life should not be underestimated. In order for family planning programs and services to be successful, the methods should be easily accessible and effective, should have no side-effects, and should be demanded by individuals (Sahin HG, Sahin HA, Zeteroğlu \& Kolusarı, 2002).

The use of birth control methods has been increasing day by day in the world. According to United Nations 2009 report, the use of contraceptive methods is $62.9 \%$ in developing countries and $70 \%$ in the developed countries (United Nations [UN], 2009). Of the married women in Turkey, 99.8\% know at least one contraceptive method and $73 \%$ use one method. Of all the women population, $46 \%$ use one of the effective family planning methods (Hacettepe University Institute of Population Studies, 2008). Various regions in our country demonstrate differences in terms of the use of family planning methods and thus the proportions of birth rates. The difference between regions can be eliminated by increasing the effectiveness of family planning services in regions and minimizing the negative factors regarding the individuals provided service.

Studies show that regulating fertility is affected by such factors as age, education level, occupation, economic status, duration of marriage, number of pregnancies, number of deliveries, and number of children alive (Ali, Okud, 2013; Palamuleni, 2013; Oltuluoglu, Baser, 2012). Factors in relation to the individuals who are provided service demonstrate findings regarding demographic data. However, knowledge of the effects of culture, traditions, and myths on the use of family planning methods is limited. Knowing about these beliefs is considered to be important in that it helps health professionals to plan health services that increase the use of effective methods.

\section{Purpose}

This study aims to identify people's misconceptions regarding family planning methods.

\section{Method and material}

\subsection{The place and time of the study}

The study population consisted of women who attended to a family planning clinic of a state hospital between January -May 2012 in Karaman (Turkey).

\subsection{Population and sample selection}

The universe of research was included 1335 women aged between 16 and 56 years, who were willing to participate in the survey and complied with the criteria between January-May 2012. 
Demirgöz Bal, M., \& Aydın Özkan, S. (2015). Misconceptions about family planning of women in Turkey. International Journal of Human Sciences, 12(1), 1319-1329. doi: 10.14687/ijhs.v12i1.2895

\subsection{Type of study}

This study was planned as a cross-sectional research.

\subsection{Data collection}

The data were collected by using the "Women Identification Form" regarding the demographic features and use of family planning and myths/misconceptions. The variables were age, education status, marital status, number of pregnancy, birth, abortion and curettage, used family planning methods, misconceptions about the method of family planning. The data were collected with a face-to-face interview technique using a questionnaire.

\subsection{Limitations of the study}

The results of the study cannot be generalized because of the small number of sample group and selection method.

\subsection{Research ethics}

Data were collected after getting permission from Karaman Local Health Authority considering voluntariness. Participants were informed of the purpose and procedure of the study. Oral and written consents were obtained from the informants.

\section{Results}

A total of 1335 women, aged between 16 and 56 years, participated in the study. All women have been living in the center of the city. The mean (SD) age of the participants was $32.79 \pm 8.8$ (16-56) years. When the obstetric findings investigated, it was found the average number of

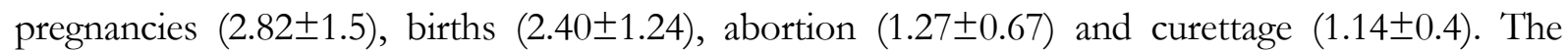
characteristics of the participants are shown in Table 1.

Table 1:The descriptive characteristics of the participants

\begin{tabular}{lll}
\hline Characteristics & $\mathbf{n}$ & $\mathbf{\%}$ \\
\hline Age & & \\
16-25 years old & 304 & 22.8 \\
26-35 years old & 550 & 41.2 \\
36 years old and older & 481 & 36.0 \\
\hline Educational Status & & \\
8 years and lower & 824 & 61.7 \\
8 years and higher & 511 & 38.3 \\
\hline Marital Status & & \\
Married & 1288 & 96.5 \\
Single & 47 & 3.5 \\
\hline
\end{tabular}

While $6.2 \%(n=84)$ of the women used no contraceptive method, $70.4 \%(n=945)$ of them used an effective method and 23.4\% ( $\mathrm{n}=312)$ used a traditional method (Table 2$)$. 
Demirgöz Bal, M., \& Aydın Özkan, S. (2015). Misconceptions about family planning of women in Turkey. International Journal of Human Sciences, 12(1), 1319-1329. doi: 10.14687/ijhs.v12i1.2895

Table 2: The distributions of family planning methods used

\begin{tabular}{lll}
\hline Contraceptive Methods & $\mathbf{n}$ & $\mathbf{0}$ \\
\hline Condom & 354 & 26.5 \\
Combined oral contraceptives (COC) & 307 & 23.0 \\
Withdrawal & 312 & 23.4 \\
Intrauterine devices (IUD) & 172 & 12.9 \\
Tubal ligation & 72 & 5.4 \\
No methods & 84 & 6.2 \\
Injection & 28 & 2.1 \\
Implant & 6 & 0.5 \\
\hline
\end{tabular}

The participants had misconceptions about COC most by $40.2 \%$, followed by IUD by $24.2 \%$ and injection method by $12.5 \%$.

The statistical analyses showed that the participants, who had misconceptions about the method of family planning, could never think of usage of related method. Table 3 shows the distribution of misconception and contraceptive methods and their percentages.

Table 3: Distribution of the misconceptions and contraceptive methods

\begin{tabular}{|c|c|c|c|c|}
\hline Contraceptive & Methods & Misconceptions & $\mathbf{n}$ & $\%$ \\
\hline \multirow[t]{9}{*}{$\mathrm{COC}$} & $(n=734,40.2 \%)$ & & & \\
\hline & & Weight gain & 195 & 10.7 \\
\hline & & Infertility & 151 & 8.2 \\
\hline & & Bleeding disorder & 148 & 8.2 \\
\hline & & Hirsutism & 92 & 5.1 \\
\hline & & Cancer & 89 & 4.8 \\
\hline & & Irritability & 22 & 1.2 \\
\hline & & Malformed baby & 21 & 1.1 \\
\hline & & Premature menopause & 16 & 0.9 \\
\hline \multirow[t]{7}{*}{ IUD } & $(n=442,24.2 \%)$ & & & \\
\hline & & Bleeding disorder & 170 & 9.3 \\
\hline & & Moving in the body & 118 & 6.4 \\
\hline & & Cancer & 63 & 3.5 \\
\hline & & Decreased sexual desire & 28 & 1.6 \\
\hline & & Genital infection & 37 & 2.1 \\
\hline & & Infertility & 26 & 1.3 \\
\hline \multirow[t]{7}{*}{ Injection } & $(n=229,12.5 \%)$ & & & \\
\hline & & Bleeding disorder & 66 & 3.6 \\
\hline & & Cancer & 31 & 1.7 \\
\hline & & Weight gain & 45 & 2.4 \\
\hline & & Infertility & 42 & 2.3 \\
\hline & & Hirsutism & 24 & 1.3 \\
\hline & & Premature menopause & 21 & 1.2 \\
\hline \multirow[t]{3}{*}{ Condom } & $(n=95,5.2 \%)$ & & & \\
\hline & & Decreased sexual performance & 76 & 3.0 \\
\hline & & Pain & 19 & 0.5 \\
\hline \multicolumn{5}{|c|}{ Female condom $(n=16,0.8 \%)$} \\
\hline & & Decreased sexual desire & 16 & 0.8 \\
\hline Vasectomy & $(n=115,6.3 \%)$ & & & \\
\hline
\end{tabular}


Demirgöz Bal, M., \& Aydın Özkan, S. (2015). Misconceptions about family planning of women in Turkey. International Journal of Human Sciences, 12(1), 1319-1329. doi: 10.14687/ijhs.v12i1.2895

\begin{tabular}{lllll}
\hline & & Decreased sexual performance & 115 & 6.3 \\
\hline Tubal ligation & $(\mathbf{n}=\mathbf{8 5 , 4 . 7 \% )}$ & & \\
\hline & & Decreased sexual performance & 85 & 3.0 \\
& & Premature menopause & 30 & 1.7 \\
\hline Implant & $(\mathbf{n = 3 2 , 1 . 8 \% )}$ & & & \\
\hline & & Moving in the body & 15 & 0.8 \\
& & Cancer & 6 & 0.4 \\
& & Infertility & 6 & 0.4 \\
& & Bleeding disorder & 5 & 0.2 \\
\hline Diaphragm & $\mathbf{( n = 1 7 , 0 . 9 \% )}$ & & \multicolumn{2}{c}{} \\
\hline & & Infection & 10 & 0.6 \\
& & Decreased sexual desire & 7 & 0.3 \\
\hline
\end{tabular}

\section{Discussion}

In this study, $71 \%$ out of the women used an effective family planning method. The most common misconceptions were the COC (40.2\%), IUD (24.2\%) and injected contraceptives $(12.5 \%)$, respectively. The probable reason of this order of the misconceptions about these methods might be the fact that these methods are the most known effective methods in Turkey. Indeed, the women also stated that they would certainly not use the methods about which they had myths. This can affect the distribution of usage of methods in future. Nearly half of the women in the study believed in that oral contraceptive methods caused weight gain, infertility, bleeding disorders, hirsutism, cancer, and premature menopause. Similarly to the results of this study, the women in Gilliam et al.'s study believed in that the oral contraceptives caused weight gain (Gilliam, Warden, Goldstein, \& Tapia, 2004).

Also, in a study by Kücük et al.'s $45.2 \%$ out of 418 women believed that the usage of oral contraceptives caused weight gain (Kücük, Aksu \& Sezen, 2012). Although this belief of women, a study done with total 1916 women in America by Brunner et al. (2005) identified no statistically significant relationship among body mass index (BMI) and the weight gain and the usage of oral contraceptives (Brunner \& Hogue, 2005). It has been found no difference between the case group and the control group about the weight gain and usage of oral contraceptive methods in a systematic review of the Cochrane database in 2011 (Gallo, Lopez, Grimes, Schulz, \& Helmerhorst, 2011). That was probably caused by the fact that the weight changes naturally as life circumstances change and as women age and because these changes in weight are so common, many women think that the oral contraceptive causes these gains in weight.

The participants believed that they would be infertile after the usage of oral contraceptives. Similarly, in another study done in Turkey, 13.4\% of the women had the same opinion (Kücük et al., 2012). In a study performed in Pakistan, $61 \%$ of the women had the same belief, which was 
Demirgöz Bal, M., \& Aydın Özkan, S. (2015). Misconceptions about family planning of women in Turkey. International Journal of Human Sciences, 12(1), 1319-1329. doi: 10.14687/ijhs.v12i1.2895

very higher than those of our study (Ali et al., 2011). Although in some publications it has been claimed that there would be a delay in pregnancy after the usage of oral contraceptives, there is no clear evidence that the usage of oral contraceptives causes infertility (World Health Organization, 2009).

Another misconception about the use of combined oral contraceptives has been the concern that it would cause bleeding disorder. There are other similar studies reporting on the same concerns (Gilliam et al., 2004). On the other hand, in the literature it has been determined that this method can be used in the treatment of bleeding disorder (Farquhar \&Brown, 2009).

In many studies in different countries, women have thought of that oral contraceptives are responsible for cancer (Gilliam et al., 2004; Guendelman, Denny, Mauldon, \& Chetkovich, 2000; Sahin, Sahin, Zeteroglu, \& Kolusar1, 2002; Vogt \& Schaefer, 2011). The results of population-based studies investigating the relationship between the usage of oral contraceptives and cancer risk are not consistent with each other. It is shown in research studies that while the usage of oral contraceptives causes in a decrease of the risk of endometrial and ovarian cancer, the usage of oral contraceptives causes in an increase in the risk of breast, cervical and liver cancer (Burkman, Schlesselman, \& Zieman, 2004; Delgado-Rodriguez, Sillero-Arenas, Martin-Moreno, \& GalvezVargas, 1992; Lurie et al, 2008; Kumle, Weiderpass, Braaten, Adami, \& Lund 2004). For this reason, we believe that the women's concerns about cancer should not be denied.

In parallel to our study, the women in Gilliam et al.'s study believed in that the oral contraceptives caused depression and mood disorders (Gilliam et al., 2004). Guendelman et al.'s (2000) proved that the women using oral contraceptives suffered from irritability, emotional stress and mood disorders (Guendelman et al., 2000). In another study Rapkin et al. (2006) investigated the relationship between the usage of oral contraceptives and irritability/mood disorders. As a result of this study it has been found that the women did not experience any psychological symptoms when they took low-dose oral contraceptives (Rapkin, Morgan, Sogliano, Biggio, \& Concas, 2006).

Another barrier found by this study against the usage of contraceptives has been the belief that the birth defects could happen. Although unaware usage of oral contraceptives in the early stages of pregnancy was claimed to cause VACTERL (Vertebral anomalies, Anal atresia, Cardiac defects, Tracheoesophageal fistula and/or Esophageal atresia, Renal \& Radial anomalies and Limb defects) syndrome in the 1970s, these findings were proven later to be incorrect in well-controlled and unbiased epidemiologic studies (Harlap, Shiono \& Ramcharan, 1985; Baumann, Greinacher, Emmrich, \& Spranger, 1976). In recent years, Waller et al.'s study (2010), similarly to other previous studies proved that no increase was observed in most types of congenital malformation in women 
Demirgöz Bal, M., \& Aydın Özkan, S. (2015). Misconceptions about family planning of women in Turkey. International Journal of Human Sciences, 12(1), 1319-1329. doi: 10.14687/ijhs.v12i1.2895

usage of OCs during early pregnancy (Waller et al., 2010). That is why, by counseling the women on the benefits, side-effects and risks of OC use, and how to take the tablets correctly and compliantly, prevent unwanted pregnancies; OCs can impact significantly on women's lives.

In Gilliam et al.'s study, the women believed that IUD would stick to the fetus and cause genital infections (Gilliam et al, 2004). A study from India reported common beliefs that IUD would move in the abdomen and cause menstrual problems and infertility. In Ali et al.'s study 53\% out of the women thought of that IUD would lead to infertility (Ali et al, 2011). Khan et al. identified similarly some worries that IUD would move inside the body and rust inside and cause infertility. It is an interesting point in Khan et al.'s study that the health care professionals had also worries that the fertility would be delayed and cause pain and discomfort and the infection would spread into the whole body after IUD removal (Khan \& Shaikn, 2013). It plays a very important role on this subject that the intrauterine device called Dalkon Shield significantly has increased pelvic inflamation. Although this was many years ago, the device was withdrawn from the market and much safer devices were produced since then, the negative thinking caused by it has remained to this day (Kimble-Haas, 1998). This study identified similar concerns about IUD.

A particular worry reported by research studies has been that IUD would move inside the body (Gilliam et al., 2004). All of these worries could have been caused by the lack of sufficient knowledge about the anatomy and physiology of human reproductive? Therefore, IUD services without a proper training about these devices have not been sufficient to resolve the worries and myths. Rigid patient selection for IUD, strict aseptic technique and a proper training to prevent the wrong beliefs can be applied by nurses. Burrough et al.'s emphasized the significance of the consulting support by specially trained midwives and nurses who have proved to be capable of offering qualified consulting (Burroughs, Dmytrow, \& Lewis, 2007).

In a study done with married women in a slum area of Delhi revealed that the women believed in that the injected contraceptives would cause infertility (Singh, Khokar, Pagare, Sharma, \& Mehra, 2003). In a study done with South African women, it is found that the women believed in that the injected contraceptives would cause infertility, sexual reluctance (loss of libido), menstrual disturbances, and weight gain (Morroni, Myer, Moss, \& Hoffman, 2006). The results of this study also showed that women in Turkey had the same worries. However, in contrast to all of these beliefs, there was no evidence to suggest that prolonged use of Depo-Provera increases the delay before conception, and the return of fertility among never pregnant ex-users resembled that of ever pregnant ex-users (Pardthaisong, Gray, \& McDaniel, 1980). In our study, using condoms would cause a decrease in sexual performance and pain was identified as the primary concern. In a qualitative study done in Pakistan with married couples between the ages of 18 to 24, the 
Demirgöz Bal, M., \& Aydın Özkan, S. (2015). Misconceptions about family planning of women in Turkey. International Journal of Human Sciences, 12(1), 1319-1329. doi: 10.14687/ijhs.v12i1.2895

participants thought that using condoms would cause sexual reluctance, particularly low back pain and infection (Nishtar, Sami, Faruqi, Khowaja, \& Ul-Hasnain, 2012).

A study done in the north of India similarly reported some common beliefs that using condoms would cause lack of sex sensation, weakness, and menstrual problems (Bajwa, Bajwa, Ghai, Singh, \& Singh, 2012). Crosby et al.'s also reported research results supporting the worries related to sexuality. They determined that the men and women who had used condoms in the last three weeks of their sexual intercourses suffered from decreased sensation, lack of naturalness, decreased pleasure, and pain and discomfort associated with using condoms (Crosby et al., 2013). The worry has been reported by research studies that norplant remaining in the body for a long time like IUD would move in the body (Gilliam et al, 2004). All of these worries could have been caused by the lack of sufficient knowledge about the anatomy and physiology of human reproductive organs. Therefore, offering IUD services without a proper training about these devices have not been sufficient to resolve the worries and myths.

The participants in this study believed that vasectomy and tubal ligation would cause a decrease in sexual performance. The research studies done in Pakistan and Delhi also reported worries that vasectomy would cause impotency and weakness (Singh et al, 2003; Nishtar et al., 2012). In Shih et al.'s the women and men from all racial/ethnic groups reported a fear of longterm effects of vasectomy on sexual function. Determination of the same worries in research studies done in different countries, in different cultures and at different times seems noteworthy (Shih, Dubé, Sheinbein, Borrero, \& Dehlendorf, 2013). On the other hand, contrary to the popular belief, Bertero et al.'s reported that vasectomy caused a positive impact on sexual function, especially on desire and sexual satisfaction, in the majority of men undergoing surgery (Bertero, Hallak, Gromatzky, Lucon, \& Arap, 2005). In addition, Li et al.'s showed that, after female sterilization, there was a significant improvement in sexual satisfaction and sexual desire. Therefore, the media campaign featured satisfied vasectomy and tubal ligation users to create awareness of and a positive image for vasectomy and tubal ligation (Li et al., 2011).

In Turkey, the female fertility is highly important to be regarded as "woman" by themselves and by the society. For this reason, even if Turkish women want to use family planning methods for a period of time, they are usually worried about that many of those methods could cause infertility and premature menopause, as seen in most of the methods mentioned above. According to the comprehensive review by Mansour et al., it has been found that one-year pregnancy rates following cessation of oral contraceptives, contraceptive implants and monthly injections, copper IUDs and the LNG (Levonorgestrel)- IUD are broadly similar to those 
Demirgöz Bal, M., \& Aydın Özkan, S. (2015). Misconceptions about family planning of women in Turkey. International Journal of Human Sciences, 12(1), 1319-1329. doi: 10.14687/ijhs.v12i1.2895

reported following discontinuation of barrier methods or use of no contraceptive methods

(Mansour, Gemzell-Danielsson, Inki, \& Jensen, 2011).

\section{Conclusions and recommendations}

There are many myths and misconceptions surrounding contraception, and they can sometimes prevent a woman from making an informed choice. It is the responsibility of the health professional to be well-informed so that when these myths and misconceptions are raised, they can be challenged with an accurate response. The problem appears to be a health and education issue rather than a pure problem of family planning.

\section{References}

Ali, A.A., Okud, A. (2013). Factors affecting unmet need for family planning in Eastern Sudan. BMC Public Health, 13, 102. DOI: 10.1186/1471-2458-13-102.

Ali, S., Sophie, R., Imam, A.M., Khan, F.I., Ali, S.F., Shaikh, A., \& Hasnain S.F. (2011). Knowledge, perceptions and myths regarding infertility among selected adult population in Pakistan: a cross-sectional study. BMC Public Health, 4(11),760-767. DOI: 10.1186/1471-2458-11-760.

Bajwa, S.K., Bajwa, S.J., Ghai, G.K., Singh, K., \& Singh N. (2012). Knowledge, attitudes, beliefs, and perception of the north Indian population toward adoption of contraceptive practices. Asia Pac J Public Health, 24(6),1002-1012. DOI: 10.1177/1010539511411473.

Baumann, W., Greinacher, I., Emmrich, P., \& Spranger, J. (1976). Vater or vacterl syndrome (author's transl). Klin Padiatr, 188(4),328-337.

Bertero, E., Hallak, J., Gromatzky, C., Lucon, A.M., \& Arap, S. (2005). Assessment of sexual function in patients undergoing vasectomy using the international index of erectile function. Int Braz J Urol, 31(5),452-458.

Brunner, L.R., \& Hogue, C.J. (2005). The role of body weight in oral contraceptive failure: Results from the 1995 National Survey of Family Growth. Ann Epidemiol, 15,492-499.

Brown, G.F. (1984). United Nations International Conference on Population, Mexico City, 6-13 August 1984. Studies in Family Planning, 15(6),296-302.

Burkman, R., Schlesselman, J.J., \& Zieman, M. (2004). Safety concerns and health benefits associated with oral contraception. Am J Obstet Gynecol, 190,5-22. DOI:10.1016/j.ajog.2004.01.061

Burroughs, R., Dmytrow, B., Lewis, H. (2007). Trends in nurse practitioner professional liability: an analysis of claims with risk management recommendations. J Nurs Law, 11(1),53-60.

Crosby, R.A., Milhausen, R.R., Mark, K.P., Yarber, W.L., Sanders, S.A., \& Graham, C.A. (2013). Understanding problems with condom fit and feel: an important opportunity for improving clinic-based safer sex programs. J Prim Prev, 34(1-2),109-115. DOI: 10.1007/s10935-013-0294-3.

Delgado-Rodriguez, M., Sillero-Arenas, M., Martin-Moreno, J.M.,\& Galvez-Vargas, R. (1992). Oral contraceptives and cancer of the cervix uteri. A meta-analysis. Acta Obstet Gynecol Scand,.71(5),368-376. 
Demirgöz Bal, M., \& Aydın Özkan, S. (2015). Misconceptions about family planning of women in Turkey. International Journal of Human Sciences, 12(1), 1319-1329. doi: 10.14687/ijhs.v12i1.2895

Farquhar, C., \& Brown, J. (2009). Oral contraceptive pill for heavy menstrual bleeding. Cochrane Database of Syst Rev, 7(4), CD000154. DOI: 10.1002/14651858.

Gallo, M.F., Lopez, L.M., Grimes, D.A., Schulz, K.F., \& Helmerhorst, F.M. (2011). Effect of birth control pills and patches on weight. Cochrane Database Syst Rev, 7(9). Art. No.: CD003987. DOI: 10.1002/14651858.CD003987

Gilliam, M.L., Warden, M., Goldstein, C, \& Tapia, B. (2004). Concerns about contraceptive side effects among young Latinas: a focus-group approach. Contraception, 70,299-305.

Guendelman, S., Denny, C., Mauldon, J., \& Chetkovich, C. (2000). Perceptions of hormonal contraceptive safety and side effects among low-income Latina and Non-Latina women. Matern Child Health J, 4(4),233-239.

Hacettepe University Institute of Population Studies. (2008). Turkey Demographic and Health Survey TDHS-2008. Retrieved September 08, 2013, from http://www.hips.hacettepe.edu.tr/eng/tdhs08/TDHS-2008_Main_Report.pdf

Harlap, S., Shiono, P.H., \& Ramcharan, S. (1985). Congenital abnormalities in the offspring of women who used oral and other contraceptives around the time of conception. Int J Fertil, 30(2),39-47.

Khan, A., \& Shaikh, B.T. (2013). An all time low utilization of intrauterine contraceptive device as a birth spacing method--a qualitative descriptive study in district Rawalpindi, Pakistan. Reprod Health, 10(10),1-5. DOI: 10.1186/1742-4755-10-10.

Kimble-Haas, S.L. (1998). The intrauterine device: dispelling the myths. Nurse Pract, 23(11),63-69.

Kumle, M., Weiderpass, E., Braaten, T., Adami, H.O., \& Lund, E. (2004). Risk for invasive and borderline epithelial ovarian neoplasias following use of hormonal contraceptives: the Norwegian-Swedish Women's Lifestyle and Health Cohort Study. Br J Cancer, 90(7),13861391.

Küçük, M., Aksu, H., \& Sezer, S.D. (2012). Misconceptions about the side effects of combined oral contraceptive pills. Gynecol Endocrinol, 28(4),282-285. DOI: 10.3109/09513590.2011.613502.

Li, R.H., Lo, S.S., Teh, D.K., Tong, N.C., Tsui, M.H., Cheung, K.B., \& Chung, T.K. (2004). Impact of common contraceptive methods on quality of life and sexual function in Hong Kong Chinese women. Contraception, 70(6),474-482.

Lurie, G., Wilkens, L.R., Thompson, P.J., McDuffie, K.E., Carney, M.E., Terada, K.Y., Goodman, M.T. (2008). Combined oral contraceptive use and epithelial ovarian cancer risk: time-related effects. Epidemiology 19(2),237-243. DOI: 10.1097/EDE.0b013e31816334c5

Mansour, D., Gemzell-Danielsson, K., Inki, P., \& Jensen, J.T. (2011). Fertility after discontinuation of contraception: a comprehensive review of the literature. Contraception, 84(5),465-477. DOI: $10.1016 /$ j.contraception.2011.04.002

Ministry of Health General Directorate of Mother and Child Health and Family Planning. (2010). Sexual and Reproductive Health, National Strategic Action Plan for the Health Sector 2005-2015. Retrieved October 10, 2013, from http://sbu.saglik.gov.tr/Ekutuphane/kitaplar/a\%C3\%A7sap9.pdf

Morroni, C., Myer, L., Moss, M., \& Hoffman, M. (2006). Preferences between injectable contraceptive methods among South African women. Contraception, 73(6),598-601. 
Demirgöz Bal, M., \& Aydın Özkan, S. (2015). Misconceptions about family planning of women in Turkey. International Journal of Human Sciences, 12(1), 1319-1329. doi: 10.14687/ijhs.v12i1.2895

Nishtar, N.A., Sami, N., Faruqi, A., Khowaja, S., \& Ul-Hasnain, F. (2012). Myths and fallacies about male contraceptive methods: A qualitative study amongst married youth in slums of Karachi, Pakistan. Glob J Health Sci, 5(2),84-93. doi: 10.5539/gjhs.v5n2p84.

Oltuluoğlu H., ,Başer M. (2012). The evalution of birth control methods and causes of mehhod preference among married women in Malatya. Journal of Turgut Ozal Medical Center, 19(3), $167-74$.

Palamuleni, M.E. (2013). Socio-economic and demographic factors affecting contraceptive use in Malawi. Afr J Reprod Health,17(3), 91-104.

Pardthaisong, T., Gray, R.H., \& McDaniel, E.B. (1980). Return of fertility after discontinuation of depot medroxyprogesterone acetate and intra-uterine devices in Northern Thailand. Lancet, 1(8167),509-512.

Rapkin, A.J., Morgan, M., Sogliano, C., Biggio, G., \& Concas, A. (2006). Decreased neuroactive steroids induced by combined oral contraceptive pills are not associated with mood changes. Fertil Steril, 85(5):1371-1378.

Sahin, H.G., Sahin, H.A, Zeteroglu, S., \& Kolusar1, A. (2002). Reasons for not using family planning methods in Van region. Journal of Gynecology and Obstetrics, 12(3),265-268.

Shih, G., Dubé, K., Sheinbein, M., Borrero, S, \& Dehlendorf, C. (2013). He's a Real Man: A Qualitative Study of the Social Context of Couples' Vasectomy Decisions Among a Racially Diverse Population. Am J Mens Health, 7(3),206-213. DOI: $10.1177 / 1557988312465888$

Singh, C.M.M., Khokar, A., Pagare, D., Sharma, N., \& Mehra, M. (2003). A study of contraceptive use among ever-married muslim women in an urban slum of Delhi. Health Popul Perspect Issues, 26(1),10-15.

United Nations.(2009). World contraceptive use 2009. United Nation, Department of Economic and Social Affairs, Population Division. Retrieved September 08, 2013, from http://www.un.org/esa/population/publications/contraceptive2009/contracept2009_wa llchart_front.pdf.

Vogt, C., \& Schaefer, M. (2011). Disparities in knowledge and interest about benefits and risks of combined oral contraceptives. Eur J Contracept Reprod Health Care, 16(3),183-93. DOI: 10.3109/13625187.2011.561938.

Waller, D.K, Gallaway, M.S., Taylor, L.G., Ramadhani, T.A., Canfield, M.A., Scheuerle, A., et al. (2010). Use of oral contraceptives in pregnancy and major structural birth defects in offspring. Epidemiology, 21(2),232-239. DOI: 10.1097/EDE.0b013e3181c9fbb3.

World Health Organization. (2009). Medical eligibility criteria for contraceptive use. Forth edition. P5 ISBN9789241563888 Retrieved October 12, 2013 from http://www.whqlibdoc.who.int/publications/2010/9789241563888_eng.pdf 